\title{
Investigating the function of single nucleotide polymorphisms in the CTSB gene: a computational approach
}

\author{
Nitin Chitranshi ${ }^{* 1,2}$, Amit K Tiwari ${ }^{3}$, Pallavi Somvanshi ${ }^{4}$, Pushpendra K Tripathi ${ }^{2}$ \\ \& Prahlad K Seth ${ }^{1}$ \\ 'Bioinformatics Centre, Biotech Park, Sector-G, Jankipuram, Lucknow-226021, Uttar Pradesh, India \\ ${ }^{2}$ Gautam Buddh Technical University, Lucknow 227202, Uttar Pradesh, India \\ ${ }^{3}$ Department of Biomedical Sciences, College of Veterinary Medicine, Nursing \& Allied Health, Tuskegee \\ University, Tuskegee, AL 36088, USA \\ 4Department of Biotechnology, TERI University, 10, Institutional Area, Vasantkunj, New Delhi 110070, India \\ *Author for correspondence: Tel.: +919473896002 =nitin0916@gmail.com
}

Aim: Recent genome-wide association studies have revealed large numbers of single nucleotide polymorphisms (SNPs) related to Alzheimer's disease. Here, we have investigated the gene CTSB, which plays a crucial role in encoding CTSB, a lysosomal cysteine proteinase protein. CTSB is also involved in the proteolytic processing of amyloid precursor protein (APP), which is believed to be a causative factor in Alzheimer's disease. Materials \& methods: Several bioinformatics algorithms such as, Sorting Intolerant from Tolerant (SIFT), Polymorphism Phenotyping (PolyPhen) and CUPSAT could identify the synonymous SNPs and nonsynonymous SNPs (nsSNPs), which are predicted to be deleterious and nondeleterious, respectively. Similar tools were used to predict the impact of single amino acid substitutions on CTSB protein activity. The FASTSNP server and UTRscan were used to predict the influence on splicing regulations. The stability and solvent-accessible surface area of modeled mutated proteins were analyzed using PBEQ solver and NetASA view. Furthermore, the DSP program was used to determine the secondary structures of the modeled protein. Results: A total of 999 SNPs in CTSB were retrieved from the SNP database; 55 nsSNPs, 35 synonymous SNPs, 165 mRNA were found in the 3'untranslated region SNPS, 12 SNPs were found in the 5 ' untranslated region in addition to 732 intronic SNPS. Potential functions of SNPs in the CTSB gene were identified using different web servers. For example, SIFT, PolyPhen and CUPSAT servers predicted ten nsSNPs to be intolerant, three nsSNPs to be damaging and eight nsSNPs to have the potential to destabilize protein structure. The FASTSNP server predicted 12 SNPs to influence splicing regulation, whereas two SNPs could predict a risk in the range of 3-4 (medium to high). Furthermore, mutant proteins were modeled and the total energy values were compared with the native CTSB protein. It was observed that on the surface of the protein, a mutation from threonine to serine at position 235 (rs17573) caused the greatest impact on stability. Conclusion: The genome-wide association studies database has already found rs7003814 of the CTSB gene reported against Alzheimer's disease. Our study demonstrates the presence of other deleterious nsSNPs, which may play a crucial role in predicting Alzheimer's disease risk.

Single nucleotide polymorphisms (SNPs) occur when a single base pair in a genome sequence is altered; this represents one of the most common forms of genetic variation in a human population [1]. Nonsynonymous SNPs (nsSNPs) are usually seen in the gene-coding regions that result in the alteration of amino acid residues. Currently, the public SNP database (dbSNP [101]) reports 187.9 million SNPs, of which 53.6 million have been validated. SNPs are important markers that help construct dense genetic maps. Moreover, functional polymorphic variant SNPs are directly involved in common and genetically complex diseases as well as drug responses. For example:

- SNPs introduce biological variations directly within the coding regions of functional genes and into their gene products through missense substitutions or premature termination codon [2];

- SNPs may alter gene expression by affecting regulatory elements present in noncoding regions [3];

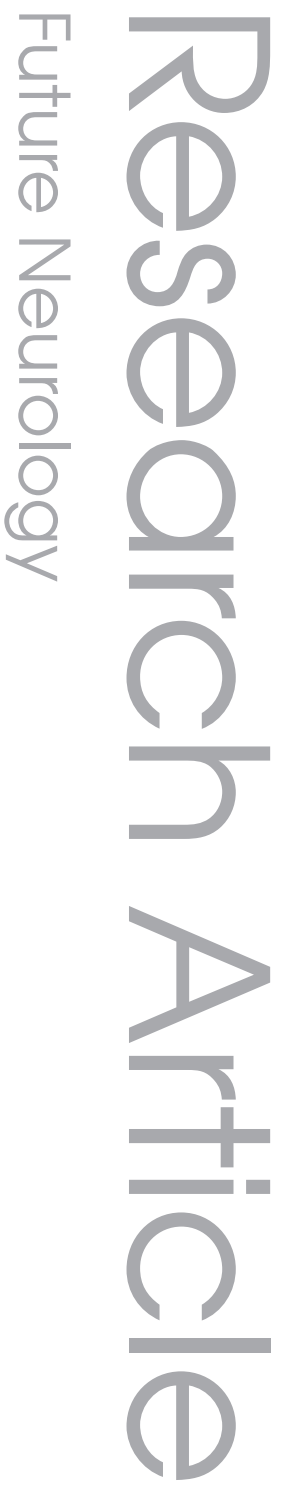

\section{Keywords}

- Alzheimer $\approx \mathrm{CTSB} \approx \mathrm{CTSB}$ gene $=\mathrm{SNP}$

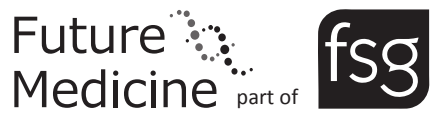


- Some intronic SNPs may activate cryptic splice sites, leading to alternative splicing [4].

SNP information is currently recorded in several databases, including: dbSNP [101], the Human Genome Variation Database (HGVbase) [5], the Japanese SNP database (JSNP) [6] and the HapMap Project [102]. A number of studies and projects have begun to explore the effects of nsSNPs on the tertiary structure of proteins and their functionality, including: SNPs3D [7], PolyPhen [8], TopoSNP [9], ModSNP [10], LSSNP [11], SNPeffect [12], MutDB [13] and Snap [14], and these are open for public use.

In this study, we have applied web-based computational tools to identify potentially functional SNPs influencing protein stability, binding of splicing modifiers, binding of transcription factors and binding of miRNA in CTSB. The protein encoded by the CTSB gene is a lysosomal cysteine proteinase composed of a dimer of disulfide-linked chains, which is produced from a single protein precursor [15-18]. The CTSB gene is mapped to location 8p22 [19] and has seven exons spanning approximately $25.7 \mathrm{~kb}$ [20]. Characterization of cDNAs encoding human, mouse and bovine CTSB has revealed that cysteine proteinase is synthesized as a preproenzyme that undergoes post-translational processing during its transport to the lysosomal compartment [21]. The CTSB gene encodes the protease CTSB, which plays an important role in lysosomal proteolysis and turnover of proteins [22]. Due to the overabundance of SNPs, population-based genotyping to target diseases linked to SNPs is an arduous exercise and is not cost effective. Most SNP studies have focused on the coding and regulatory region; however, at the molecular level, there has only been limited success in linking SNPs with disease susceptibility. In this study, mutant protein structures were modeled and the changes in energy and root mean square deviation (RMSD) values were compared with the native structure of the gene product CTSB.

The computational study focuses on the identification of functional SNPs in most of genomic regions of the human CTSB gene as compared with the recent bioinformatics studies, which were more focused on identification of deleterious nsSNPs [23-25]. This approach could help to prioritize SNP selection for genotyping in molecular studies, and eventually may help to reduce the economic burden of population-based genotyping to select disease culpable SNPs.

\section{Materials \& methods \\ Data set}

The dbSNP was used to retrieve SNPs and their related protein sequences for the CTSB gene $[26,101]$.

\section{Functional prediction of amino acid substitution variations in protein coding regions}

Deleterious nsSNPs were detected using Sorting Intolerant from Tolerant (SIFT) [27-29]. SIFT can predict whether an amino acid substitution affects protein function, which is based on the degree of conservation of amino acid residues in sequence alignments derived from closely related sequences, collected through the PSI-BLAST algorithm by searching the protein database. Homologous sequences are aligned, while the presence of any of the 20 amino acid positions is calculated. A tolerance index/SIFT score is defined based on the substitution with the normalized probabilities (i.e., a score $>0.05$ is tolerant, while $\leq 0.05$ are damaging or deleterious/intolerant) [27]. Here, we used the SIFT blink program [29], where RefSeq ID/GI number(s) and substitution(s) were given as input. Default settings were used to execute the program. For cataloging of deleterious variant(s), 12 nsSNPs in protein transcript (NP_001899.1) of the CTSB gene (NM_001908.3) were analyzed. Evolutionary and structural characteristics showing deleterious nsSNPs were analyzed using the Polymorphism Phenotyping (PolyPhen-2) tool $[30-32,103]$. PolyPhen-2 uses substitution at a specific site, for example the active site or binding site; or in nonglobular proteins, the transmembrane region. It identifies a query protein as an entry in the human proteins subset of the UniProtKB/Swiss-Prot database and uses the feature table section of the corresponding entries. PolyPhen-2 selects homologs of the input sequences via a Basic Local Alignment Search Tool (BLAST) search of the Non-Redundant Database (NRDB). A known 3D protein structure is used to map the amino acid residue substitution(s), while for each of the two amino acids positionspecific independent counts (PSIC) scores are calculated. A PSIC score difference is computed and if it is $\geq 1.5$ it is assumed to be damaging. The following four categories are defined by PolyPhen to rank nsSNPs based on PSIC score:
- Probably damaging: $\geq 2.00$
- Possibly damaging: 1.50-1.99
- Potentially damaging: 1.25-1.49
- Benign: 0.00-0.99 


\section{Selecting nsSNPs that influence protein stability}

To analyze point mutation changes responsible for protein stability, Cologne University Protein Stability Analysis Tool (CUPSAT) was used [104]. By determining amino acid atom potentials and torsion angle distribution, the CUPSAT could assess the presence of amino acids around the mutation site and thus the overall stability of protein. Using CUPSTAT, we determined presence of amino acid structural features, mutational sites and information for 19 possible substitutions at the given position, to determine changes in protein stability. The Protein Data Bank (PDB) was used to acquire the CTSB gene structure (PDB ID: 2DCD [A chain]). The protein structure, native amino acid residue and its position were given as an input to the tool. A total of 12 nsSNPs were evaluated for their influence on protein stability.

\section{Defining the functional context of SNPs in the regulatory region}

The functional impacts of SNPs in regulatory regions were analyzed using FastSNP and UTRscan. Users can efficiently identify the SNPs most likely to have functional effects by using the already available web-based function analysis and selection tool for SNP, FASTSNP $[33,105]$. The FASTSNP has four component modules:

- The query module in which user can choose query by gene, SNP cluster ID (rsID), or a chromosome position as a query;

- The function module in the SNP functional effects contains seven sections, namely genomic information, functional effect summary, transcription regulatory, mRNA/protein domain effects, protein structure effects and SwissProt feature table. FASTSNP function module than evoke pipeline web services: ESEfinder [34], ESE-RESCUE [35] and FAS-ESS [36] to predict the impact of SNPs present in splicing modifier binding sites;

- The prioritization module of FASTSNP performs the necessary post-processing from the data returned from the agent pipelines;

- The function report module allows users to check the sequence quality of SNPs and verify that a SNP specifically maps to one position in the human genome. FASTSNP computes a score based on the level of risk (i.e., $0,1,2,3$,

Table 1. Evaluation of nonsynonymous single nucleotide polymorphisms from Sorting Intolerant from Tolerant and Polymorphism Phenotyping servers.

\begin{tabular}{|c|c|c|c|c|c|c|c|c|}
\hline \multirow{2}{*}{$\begin{array}{l}\text { SNP } \\
\text { number }\end{array}$} & \multirow{2}{*}{$\begin{array}{l}\text { SNP } \\
\text { database ID }\end{array}$} & \multirow[t]{2}{*}{ Allele } & \multirow{2}{*}{$\begin{array}{l}\text { Amino acid } \\
\text { substitution }\end{array}$} & \multirow[t]{2}{*}{ Validation $^{\dagger}$} & \multicolumn{2}{|c|}{ SIFT } & \multicolumn{2}{|c|}{ PolyPhen } \\
\hline & & & & & $\begin{array}{l}\text { Tolerance } \\
\text { index }\end{array}$ & $\begin{array}{l}\text { Predicted } \\
\text { impact }\end{array}$ & PSIC & $\begin{array}{l}\text { Predicted } \\
\text { impact }\end{array}$ \\
\hline 1 & rs117636256 & $C / G$ & V232L & 1 & 0.07 & $\begin{array}{l}\text { Potentially } \\
\text { intolerant }\end{array}$ & ND & ND \\
\hline 2 & rs117613666 & T/A & Q334L & 1,2 & 0.02 & Intolerant & $N D$ & ND \\
\hline 3 & rs114308907 & T/A & N246I & 1,2 & 0.00 & Intolerant & ND & ND \\
\hline 4 & rs113867851 & $\mathrm{A} / \mathrm{T}$ & F62I & 1 & 0.41 & Tolerant & $N D$ & ND \\
\hline 5 & rs79487342 & $C / G$ & D317H & 1 & 0.00 & Intolerant & ND & ND \\
\hline 6 & rs74996838 & T/A & T75S & 1 & 0.81 & Tolerant & ND & ND \\
\hline 7 & rs73209021 & $C / G$ & G284A & 1 & 0.01 & Intolerant & ND & ND \\
\hline 8 & rs28605689 & $\mathrm{A} / \mathrm{T}$ & L26Q & 1,2 & 0.00 & Intolerant & ND & ND \\
\hline 9 & rs11548596 & $\mathrm{G} / \mathrm{C}$ & P91R & 1,2 & 0.04 & Intolerant & 0.998 & Benign \\
\hline 10 & rs1803250 & T/A & S53C & 1,2 & 0.01 & Intolerant & 1.621 & $\begin{array}{l}\text { Possibly } \\
\text { damaging }\end{array}$ \\
\hline 11 & rs17573 & $C / G$ & S235T & $1,2,3$ & 0.00 & Intolerant & 2.471 & $\begin{array}{l}\text { Probably } \\
\text { damaging }\end{array}$ \\
\hline 12 & rs12338 & $\mathrm{G} / \mathrm{C}$ & L26V & $1,2,3$ & 0.01 & Intolerant & 1.312 & $\begin{array}{l}\text { Potentially } \\
\text { damaging }\end{array}$ \\
\hline
\end{tabular}




\section{Table 2. Change in protein structure and change in free energy upon point mutation.}

\begin{tabular}{|c|c|c|c|c|c|c|c|}
\hline \multirow{2}{*}{$\begin{array}{l}\text { SNP } \\
\text { number }\end{array}$} & \multirow{2}{*}{$\begin{array}{l}\text { SNP } \\
\text { database } \\
\text { ID }\end{array}$} & \multirow{2}{*}{$\begin{array}{l}\text { Amino acid } \\
\text { substitution }\end{array}$} & \multicolumn{5}{|c|}{ Changes predicted in protein structure by CUPSAT server } \\
\hline & & & $\begin{array}{l}\text { Overall } \\
\text { stability }\end{array}$ & Torsion & $\begin{array}{l}\text { Predicted } \\
\text { change in } \\
\text { DDG } \\
\text { (kcal/mol) }\end{array}$ & $\begin{array}{l}\text { Solvent } \\
\text { accessibility } \\
(\%)\end{array}$ & $\begin{array}{l}\text { Secondary } \\
\text { structure } \\
\text { element }\end{array}$ \\
\hline 1 & rs117636256 & V232L & $\begin{array}{l}\text { Top of form } \\
\text { Destabilizing } \\
\text { Bottom of form }\end{array}$ & $\begin{array}{l}\text { Top of form } \\
\text { Favorable }\left(-116.6^{\circ}, 142.0^{\circ}\right) \\
\text { Bottom of form }\end{array}$ & -1.73 & 19.45 & Sheet \\
\hline 2 & rs117613666 & Q334L & $\begin{array}{l}\text { Top of form } \\
\text { Destabilizing } \\
\text { Bottom of form }\end{array}$ & $\begin{array}{l}\text { Top of form } \\
\text { Unfavorable }\left(-6.5^{\circ}, 130.2^{\circ}\right) \\
\text { Bottom of form }\end{array}$ & -4.67 & 2.73 & Sheet \\
\hline 3 & rs114308907 & N246I & $\begin{array}{l}\text { Top of form } \\
\text { Destabilizing } \\
\text { Bottom of form }\end{array}$ & $\begin{array}{l}\text { Top of form } \\
\text { Unfavorable }\left(-85.6^{\circ} \text {, }\right. \\
\left.132.7^{\circ}\right) \\
\text { Bottom of form }\end{array}$ & -7.97 & 1.08 & Sheet \\
\hline 4 & rs113867851 & F62I & $\begin{array}{l}\text { Top of form } \\
\text { Stabilizing } \\
\text { Bottom of form }\end{array}$ & $\begin{array}{l}\text { Top of form } \\
\text { Favorable }\left(-103.9^{\circ},-13.4^{\circ}\right) \\
\text { Bottom of form }\end{array}$ & -5.44 & 14.96 & Helix \\
\hline 5 & rs79487342 & D317H & $\begin{array}{l}\text { Top of form } \\
\text { Destabilizing } \\
\text { Bottom of form }\end{array}$ & $\begin{array}{l}\text { Top of form } \\
\text { Unfavorable }\left(-115.3^{\circ},\right. \\
\left.120.7^{\circ}\right) \\
\text { Bottom of form }\end{array}$ & -9.61 & 0.0 & Sheet \\
\hline 6 & rs74996838 & T75S & $\begin{array}{l}\text { Top of form } \\
\text { Stabilizing } \\
\text { Bottom of form }\end{array}$ & $\begin{array}{l}\text { Top of form } \\
\text { Unfavorable }\left(-110.6^{\circ},\right. \\
\left.113.6^{\circ}\right) \\
\text { Bottom of form }\end{array}$ & -0.65 & 58.79 & $\begin{array}{l}\text { Other (e.g., } \\
\text { turns, coils) }\end{array}$ \\
\hline 7 & rs73209021 & G284A & $\begin{array}{l}\text { Top of form } \\
\text { Stabilizing } \\
\text { Bottom of form }\end{array}$ & $\begin{array}{l}\text { Top of form } \\
\text { Unfavorable }\left(-129.6^{\circ},\right. \\
\left.46.9^{\circ}\right) \\
\text { Bottom of form }\end{array}$ & 0.62 & 55.42 & $\begin{array}{l}\text { Other (e.g., } \\
\text { turns, coils) }\end{array}$ \\
\hline 8 & rs28605689 & L26Q & $\begin{array}{l}\text { Top of form } \\
\text { Destabilizing } \\
\text { Bottom of form }\end{array}$ & $\begin{array}{l}\text { Top of form } \\
\text { Favorable }\left(-163.3^{\circ}, 137.9^{\circ}\right) \\
\text { Bottom of form }\end{array}$ & -4.35 & 3.56 & $\begin{array}{l}\text { Other (e.g., } \\
\text { turns, coils) }\end{array}$ \\
\hline 9 & rs11548596 & P91R & $\begin{array}{l}\text { Top of form } \\
\text { Stabilizing } \\
\text { Bottom of form }\end{array}$ & $\begin{array}{l}\text { Top of form } \\
\text { Unfavorable }\left(177.1^{\circ} \text {, }\right. \\
\left.132.7^{\circ}\right) \\
\text { Bottom of form }\end{array}$ & -1.38 & 1.27 & $\begin{array}{l}\text { Other (turns, } \\
\text { coils, among } \\
\text { others) }\end{array}$ \\
\hline 10 & rs1803250 & $\mathrm{S} 53 \mathrm{C}$ & $\begin{array}{l}\text { Top of form } \\
\text { Destabilizing } \\
\text { Bottom of form }\end{array}$ & $\begin{array}{l}\text { Top of form } \\
\text { Unfavorable }\left(84.9^{\circ}, 101.1^{\circ}\right) \\
\text { Bottom of form }\end{array}$ & -0.94 & 26.9 & $\begin{array}{l}\text { Other (e.g., } \\
\text { turns, coils) }\end{array}$ \\
\hline 11 & rs17573 & S235T & $\begin{array}{l}\text { Top of form } \\
\text { Destabilizing } \\
\text { Bottom of form }\end{array}$ & $\begin{array}{l}\text { Top of form } \\
\text { Unfavorable }\left(113.5^{\circ},\right. \\
\left.146.1^{\circ}\right) \\
\text { Bottom of form }\end{array}$ & -2.26 & 5.68 & $\begin{array}{l}\text { Other (e.g., } \\
\text { turns, coils) }\end{array}$ \\
\hline 12 & rs12338 & L26V & $\begin{array}{l}\text { Top of form } \\
\text { Destabilizing } \\
\text { Bottom of form }\end{array}$ & $\begin{array}{l}\text { Top of form } \\
\text { Unfavorable }\left(163.5^{\circ} \text {, }\right. \\
\left.137.9^{\circ}\right) \\
\text { Bottom of form }\end{array}$ & -7.97 & 3.56 & $\begin{array}{l}\text { Other (e.g., } \\
\text { turns, coils) }\end{array}$ \\
\hline
\end{tabular}

4 and 5 indicating no, very low, low, medium, high and very high risk, respectively).

The role of 5'and 3'untranslated regions (UTRs) in certain biological processes, such as translational efficiency, stability and posttranscriptional pathways has been reported previously [37,38]. UTRsite offers a compilation of user-submitted functional sequence patterns in 5'or 3'UTRs and this can be accessed through 
UTRscan program [39]. UTRscan analyzes two or three sequences of each UTR SNP that differ in nucleotide at a particular SNP position, it then scans for UTR functional elements by comparing against the patterns defined in the UTRsite and UTR databases submitted by various users. Thus, functionally differential patterns are determined for significance for each UTR SNP. The UTRsite also includes the data collected from the UTRdb, which records the functional patterns of UTR sequences from eukaryotic mRNAs [40].

\section{Modeling nsSNP locations on protein structure, determination of overall changes in energies \& their RMSD difference}

Structural analyses were performed based on the crystal structure of the protein for evaluating the structural stability of native and mutant protein. We used the web resource SNPeffect 4.0 [41] and dbSNP to identify the protein coded by the CTSB gene (PDB ID: 3PBH). We also confirmed the mutation positions and the mutation residues from this server. These mutation positions and residues were in complete agreement with the results obtained with the SIFT and PolyPhen-2 programs. The mutation was performed using SWISSPDB viewer, and energy minimization for 3D structures was performed using YASARA Energy Minimization Server [42]. This server performs energy minimization using the YASARA force field with knowledgebased dihedral potentials that are optimized to yield stable energy minima close to native $\mathrm{x}$-ray structures as described in Critical Assessment of Structure Prediction (CASP8) [42,43]. The 3D structures were optimized using the conjugate gradient method. To understand the deviation at structural level the energy was computed to ascertain the information about the protein structure stability and RMSD.

\section{Analyzing the effects of mutations on protein stability based on electrostatic potential, solvation energy, solvent accessibility \& secondary structure analysis}

The PBEQ solver [106] calculates and visualizes the electrostatic potential of molecule by solving the Poisson-Boltzmann (PB) equation. All the calculations were performed with coarse grid spacing (1.5 $\AA$ before and $1 \AA$ after focusing) for efficient calculation and visualization [44]. The ratio between the solvent-accessible surface area of a residue in the $3 \mathrm{D}$ structure and the tripeptide conformation of protein is defined as solvent accessibility. NetASAView is used to calculate the solvent accessibility. [45,107]. This can be easily determined by using the right coordinate file and/or PDB code. Based on the low, moderate and/or high accessibility of the amino acid residues to the solvent, solvent accessibility can be divided into buried, partially buried and exposed categories, respectively [46,47]. Furthermore, using the DSSP program [48], we were able to determine the secondary structures of the proteins, which is essential to understand the relationship between amino acid sequence and protein structure. The prediction of solvent

\section{Table 3. Single nucleotide polymorphisms present in splicing modifier} binding sites.

\begin{tabular}{|llll|}
\hline SNP number & SNP database ID & Possible functional effects & Risk \\
\hline 1 & rs17573 & Missense (nonconservative); splicing regulation & $3-4$ \\
\hline 2 & rs28605689 & Missense (nonconservative); splicing regulation & $3-4$ \\
\hline 3 & rs73209021 & Missense (conservative) & $2-3$ \\
\hline 4 & rs11548596 & Missense (conservative); splicing regulation & $2-3$ \\
\hline 5 & rs1137069 & Sense/synonymous; splicing regulation & $2-3$ \\
\hline 6 & rs13332 & Sense/synonymous; splicing regulation & $2-3$ \\
7 & rs11548597 & Sense/synonymous; splicing regulation & $2-3$ \\
\hline 8 & rs1803250 & Missense (conservative); splicing regulation & $2-3$ \\
\hline 9 & rs12338 & Missense (conservative) & $2-3$ \\
\hline 10 & rs2230071 & Sense/synonymous & $1-1$ \\
\hline 11 & rs2230070 & Sense/synonymous & $1-1$ \\
\hline 12 & rs4943 & Sense/synonymous & $1-1$ \\
\hline SNP: Single nucleotide polymorphism. & & \\
\hline
\end{tabular}




\begin{tabular}{|c|c|c|c|c|}
\hline $\begin{array}{l}\text { SNP } \\
\text { number }\end{array}$ & SNP database ID & $\begin{array}{l}\text { Nucleotide } \\
\text { change }\end{array}$ & UTR position & $\begin{array}{l}\text { Functional } \\
\text { element change }\end{array}$ \\
\hline 1 & rs1142982 & $A / G$ & 3'UTR & PAS \\
\hline 2 & rs1142964 & $A / G$ & 3'UTR & PAS \\
\hline 3 & rs1142963 & $A / G$ & 3'UTR & PAS \\
\hline 4 & rs1736109 & $A / G$ & $5^{\prime}$ UTR & PAS \\
\hline 5 & rs115466033 & $C / G$ & $5^{\prime} \cup T R$ & PAS \\
\hline 6 & rs1142956 & $A / G$ & 3'UTR & IRES \\
\hline 7 & rs17573 & $\mathrm{G} / \mathrm{C}$ & 3'UTR & IRES \\
\hline 8 & rs1142955 & $A / G$ & 3'UTR & IRES \\
\hline 9 & rs1138572 & $A / G$ & 3'UTR & IRES \\
\hline 10 & rs1736078 & $\mathrm{A} / \mathrm{C}$ & 3'UTR & IRES \\
\hline 11 & rs187444909 & $\mathrm{A} / \mathrm{G}$ & 3'UTR & IRES \\
\hline 12 & rs202197048 & $\mathrm{C} / \mathrm{T}$ & 5'UTR & IRES \\
\hline 13 & rs183866612 & $C / G$ & $5^{\prime} \cup T R$ & IRES \\
\hline 14 & rs144735294 & $\mathrm{C} / \mathrm{T}$ & 5'UTR & IRES \\
\hline 15 & rs1137063 & $\mathrm{C} / \mathrm{T}$ & $5^{\prime}$ UTR & IRES \\
\hline 16 & rs11548599 & $\mathrm{C} / \mathrm{T}$ & $5^{\prime}$ UTR & IRES \\
\hline 17 & rs4543503 & $\mathrm{G} / \mathrm{T}$ & $5^{\prime} \cup T R$ & IRES \\
\hline 18 & rs28605689 & $\mathrm{A} / \mathrm{T}$ & 3'UTR & MBE \\
\hline 19 & rs1142956 & $\mathrm{A} / \mathrm{G}$ & 3'UTR & MBE \\
\hline 20 & rs1803351 & $\mathrm{A} / \mathrm{T}$ & 3'UTR & MBE \\
\hline 21 & rs1736078 & $\mathrm{A} / \mathrm{C}$ & 3'UTR & MBE \\
\hline 22 & rs1803353 & $C / G$ & 3'UTR & MBE \\
\hline 23 & rs71710379 & $-/ T$ & 3'UTR & MBE \\
\hline 24 & rs62495680 & $C / G$ & 3'UTR & $\mathrm{MBE}$ \\
\hline 25 & rs34067574 & $-/ T$ & 3'UTR & MBE \\
\hline 26 & rs113669095 & $\mathrm{A} / \mathrm{C} / \mathrm{G}$ & 3'UTR & MBE \\
\hline 27 & rs111950932 & $\mathrm{G} / \mathrm{T}$ & 3'UTR & MBE \\
\hline 28 & rs189207798 & $\mathrm{C} / \mathrm{T}$ & 3'UTR & MBE \\
\hline 29 & rs4543503 & $\mathrm{G} / \mathrm{T}$ & 5'UTR & MBE \\
\hline 30 & rs202197048 & $\mathrm{C} / \mathrm{T}$ & 5'UTR & MBE \\
\hline 31 & rs183866612 & $C / G$ & 5'UTR & MBE \\
\hline 32 & rs144735294 & $\mathrm{C} / \mathrm{T}$ & 5'UTR & MBE \\
\hline 33 & rs1142955 & $A / G$ & 3'UTR & $\mathrm{KB}$ \\
\hline 34 & rs1138564 & $\mathrm{A} / \mathrm{G}$ & 3'UTR & $\mathrm{KB}$ \\
\hline 35 & rs1803249 & $\mathrm{A} / \mathrm{G}$ & 3'UTR & $\mathrm{GB}$ \\
\hline 36 & rs4987128 & $-/ C / G$ & 3'UTR & $\mathrm{GB}$ \\
\hline 37 & rs1736078 & $\mathrm{A} / \mathrm{C}$ & 3'UTR & ADH_DRE \\
\hline 38 & rs1736077 & $C / G$ & 3'UTR & ADH_DRE \\
\hline
\end{tabular}


Table 4. Summary of nonsynonymous single nucleotide polymorphisms that were predicted to have functional significance by UTRscan algorithm (cont.).

\begin{tabular}{|c|c|c|c|c|}
\hline $\begin{array}{l}\text { SNP } \\
\text { number }\end{array}$ & SNP database ID & $\begin{array}{l}\text { Nucleotide } \\
\text { change }\end{array}$ & UTR position & $\begin{array}{l}\text { Functional } \\
\text { element change }\end{array}$ \\
\hline 39 & rs28702827 & $\mathrm{A} / \mathrm{G}$ & 3'UTR & ADH_DRE \\
\hline 40 & rs11786618 & $A / G$ & 3'UTR & ADH_DRE \\
\hline 41 & rs11548592 & $\mathrm{C} / \mathrm{T}$ & 3'UTR & ADH_DRE \\
\hline 42 & rs11548590 & $\mathrm{C} / \mathrm{T}$ & 3'UTR & ADH_DRE \\
\hline 43 & rs113669095 & $\mathrm{A} / \mathrm{C} / \mathrm{G}$ & 3'UTR & TOP \\
\hline 44 & rs12338 & $\mathrm{G} / \mathrm{C}$ & 3'UTR & TOP \\
\hline 45 & rs183080071 & $\mathrm{A} / \mathrm{T}$ & 3'UTR & TOP \\
\hline 46 & rs112289724 & $\mathrm{A} / \mathrm{T}$ & 3'UTR & SXL_BS \\
\hline 47 & rs71518539 & $\mathrm{C} / \mathrm{T}$ & 3'UTR & SXL_BS \\
\hline 48 & rs56927740 & -/T/TT/TTT & 3'UTR & SXL_BS \\
\hline 49 & rs71819735 & $-/ T$ & 3'UTR & SXL_BS \\
\hline 50 & rs1736077 & $C / G$ & 3'UTR & SXL_BS \\
\hline
\end{tabular}

accessibility and secondary structure has been studied as an intermediate step for predicting the tertiary structure of proteins.

\section{Results}

\section{Data set}

The SNPs related to the CTSB gene were acquired from dbSNP database, build 137 [26]. Out of 999 SNPs, 90 (9.01\%) SNPs were present in coding region of the gene ( 55 nsSNPs and 35 synonymous SNPs), 165 SNPs (16.52\%) in the $3^{\prime}$ UTR, 732 SNPs $(73.27 \%)$ in the intron region, 12 SNP $(1.20 \%)$ in $5^{\prime}$ UTR.

\section{Concordance analysis between SIFT \& PolyPhen}

A concordance study was performed to evaluate the prediction capacity of 55 nsSNPs predicted by SIFT and PolyPhen. Ten nsSNPs were predicted to be deleterious with a tolerance less than or equal to 0.05 . The lower the tolerance index or SIFT score, the greater the functional consequence an amino acid residue substitution is expected to have [27]. Four nsSNPs (rs114308907, rs79487342, rs28605689, rs17573) had a tolerance index of 0.00, three nsSNPs (rs73209021, rs1803250, rs12338) had a tolerance index of 0.01 , one nsSNPs (rs117613666) had a tolerance index of 0.02 , and the remaining nsSNP (rs11548596) in the deleterious category had a tolerance index of 0.04 . In total, ten nsSNPs (rs117626256, rs117613666, rs114308907, rs79487342, rs11548596, rs28605689, rs73209021, rs1803250, rs17573, rs12338) out of 12 nsSNPs predicted to be deleterious had a validated status. Two nsSNPs (rs113867851, rs74996838) were predicted to have tolerant index of 0.41 and 0.81 , respectively, which were nondeleterious (Table 1). Three nsSNPs (rs1803250, rs17573, rs12338) out of 55 nsSNPs were predicted to be possibly, probably, and potentially damaging with PSIC scores of 1.621, 2.471 and

\begin{tabular}{|c|c|c|c|c|c|}
\hline $\begin{array}{l}\text { SNP } \\
\text { number }\end{array}$ & $\begin{array}{l}\text { SNP } \\
\text { database ID }\end{array}$ & $\begin{array}{l}\text { Amino acid } \\
\text { substitution }\end{array}$ & $\begin{array}{l}\text { Start energy } \\
(\mathrm{kJ} / \mathrm{mol}) / \mathrm{score}\end{array}$ & $\begin{array}{l}\text { End energy } \\
(\mathrm{kJ} / \mathrm{mol}) / \mathrm{score}\end{array}$ & RMSD (Å) \\
\hline 1 & rs11548596 & P91R & $-100,855.5 /-0.81$ & $-130,018.2 / 0.25$ & 0.01478 \\
\hline 2 & rs1803250 & S53C & $-104,289.4 /-2.80$ & $-159,274.9 /-0.41$ & 0.03562 \\
\hline 3 & rs17573 & S235T & $-101,252.2 /-0.77$ & $-109,094.6 / 0.10$ & 0.12331 \\
\hline 4 & rs12338 & L26V & $-104,124.6 /-2.80$ & $-199,441.2 /-0.52$ & 0.04114 \\
\hline
\end{tabular}



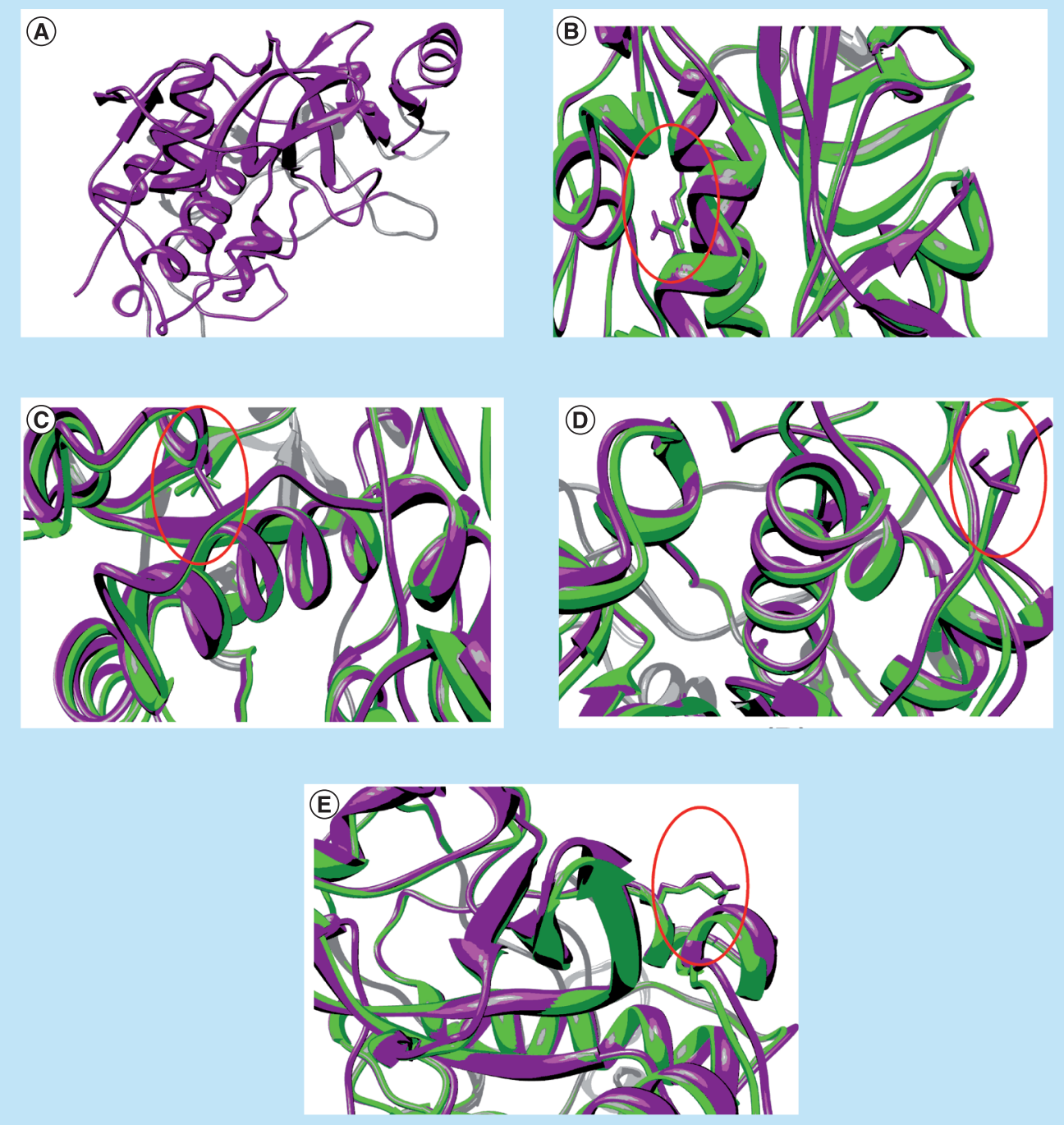

Figure 1. Native structure and mutant model of the CTSB protein. (A) Native structure of CTSB gene with ' $A$ ' chain of Protein Data Bank ID 2DCD. (B) Superimposed structure of native proline with mutant amino acid arginine at the 91 position in 2DCD with root mean square deviation (RMSD) $0.01478 \AA$. (C) Superimposed structure of native serine with mutant amino acid cysteine at the 53 position in 2DCD with RMSD $0.03562 \AA$. (D) Superimposed structure of native serine with mutant amino acid tyrosine at the 253 position in 2DCD with RMSD $0.12331 \AA$. (E) Superimposed structure of native leucine with mutant amino acid valine at the 26 position in 2DCD with RMSD $0.04114 \AA$.

1.312, respectively (TABLE 1). It was observed that one nsSNP (rs11548596), predicted to be benign damaging by PolyPhen-2, was also predicted to be deleterious by SIFT server. This shows a significant level of correlation between the results from an evolutionary-based approach (SIFT) and a structural-based approach (PolyPhen-2). The highly damaging nsSNPs (rs17573) had a PSIC score of 2.471 and SIFT score 0.00 .

\section{nsSNPs responsible for destabilizing} protein structure

CUPSAT identified eight nsSNPs (rs117636256, rs117613666, rs114308907, rs79487342, rs28605689, rs1803250, rs17573, rs12338) out of 12 nsSNPs that influence overall stability of the protein structure. Nine nsSNPs (rs117613666, rs114308907, rs79487342, rs74996838, rs73209021, rs11548596, rs1803250, rs17573, rs12338) only exhibited unfavorable changes in torsion angles with influence on overall stability of protein except rs113867851, rs74996838, rs73209021 and rs11548596 (Table 2). The nsSNP rs17573 predicted to be destabilizing to protein structure was also predicted damaging by SIFT server (SIFT score: 0.00) and PolyPhen server (PSIC score difference: 2.471 ). 


\section{Analysis of functional SNPs in the regulatory region}

Functional SNPs in the regulatory region were analyzed using FASTSNP and UTRscan. FASTSNP predicted that 12 SNPs influence splicing regulation by their presence in splicing modifier (enhancers and silencers) binding sites (Table 3) [49]. Two SNPs that were predicted to influence splicing regulation had a risk in the range of 3-4 (medium to high), seven SNPs had a risk in the range of 2-3 (low to medium) and the remaining three SNPs were in the very-low risk range of 1 (very low). To the best of our knowledge, this is the first report showing that the SNP in the splicing modifiers binding site of the CTSB gene has functional importance. None of the SNPs in UTR were reported to be present in splicing modifier binding sites and intronic regions. The UTRscan program results are depicted in Table 4. A genome-wide association study has shown that Chinese people with A/G polymorphism (rs7812879) are susceptible to systemic lupus erythematosus [50]; however, a new loci association has been reported in Kawasaki disease in a Japenese population with the same A/G polymorphism (rs2254546) [51]. There were 177 SNPs in the UTRs of the selected gene (CTSB), of which 165 were in the 3'UTR and 12 were in the 5'UTR. UTRscan was applied to prioritize 177 UTR SNPs. The program found that 47 UTR SNPs have different patterns for each sequence, which were predicted to have functional significance. Among the 47 UTR SNPs, 12 were present in the 5'UTR, and 35 were present in the $3^{\prime}$ UTR. Also, 14 of them were related to the functional pattern change of MBE (TABLE 4); 11 functional SNPs out of 47 were related to the functional pattern change of internal ribosome entry site (IRES), six of them were related to the functional pattern change of alcohol dehydrogenase 3'UTR downregulation control element, 5-5 each of them were related to the functional pattern change of SXL binding site and polyadenylation signal (PAS), and 2-2 each of them related to the functional pattern change of K-Box, GY-Box and terminal oligopyrimidine (TOP), respectively.

\section{Modeling \& analysis of mutant structure}

Single amino acid mutations can significantly change the stability of a protein structure. Therefore, the knowledge of a protein's 3D structure is essential for a full understanding of its functionality. Mapping the deleterious nsSNPs into protein structure information was obtained from dbSNP and SNP effect 4.0. The available structure for the CTSB gene is reported to have a PDB ID (2DCD). Mutation analysis was performed based on the results obtained from the highest PolyPhen scores. SWISS-PDB viewer performed the mutations for 2DCD at their corresponding positions, independently, to achieve modeled structures. Then, using the YASARA Energy Minimization Server, energy minimizations were performed for the native type protein $3 \mathrm{PBH}$ and the mutant type structures. It can be inferred from Table 1 that nsSNPs in the CTSB gene with the IDs rs11548596, rs1803250, rs17573 and rs12338, showed the highest PolyPhen scores $0.998,1.621,2.471$ and 1.312 , respectively. According to this, the mutation occurred for native protein in the 'A' chain of PDB ID 2DCD at position P91R with an SNP ID (rs11548596), S53C with an SNP ID (rs1803250), S235T with an SNP ID (rs17573) and L26V with an SNP ID (rs12338) based on PolyPhen results. It can be seen that the total energy/score for mutant type structure P91R, S53C, S235T and L26V were found to be $-130018.2 / 0.25,-159274.9 /-$ $0.41,-109094.6 / 0.10$ and $199441.2 /-0.52 \mathrm{Kcal} /$ mol, respectively. The RMSD values between the native type (2DCD) and the mutant P91R is $0.01478 \AA$, between native type and the mutant $\mathrm{S} 53 \mathrm{C}$ is $0.03562 \AA$, between native type and the mutant S253T is 0.12331 and between native type and the mutant $\mathrm{L} 26 \mathrm{~V}$ is $0.04114 \AA$. The total energy and RMSD value of mutant structure S235T is high when compared with the other mutants P91R, S53C and L26V, respectively (TAвLE 5). The higher the RMSD value the

Table 6. Solvation energy and effect of stability on mutant protein.

\begin{tabular}{|lllll|}
\hline $\begin{array}{l}\text { SNP } \\
\text { number }\end{array}$ & SNP database ID & $\begin{array}{l}\text { Amino acid } \\
\text { substitution }\end{array}$ & $\begin{array}{l}\text { Solvation energy } \\
\text { (kcal/mol) }\end{array}$ & Effect \\
\hline 1 & rs11548596 & P91R & -2178.4 & Unstable \\
\hline 2 & rs1803250 & S53C & -1567.8 & Unstable \\
\hline 3 & rs17573 & S235T & -670.6 & Highly unstable \\
\hline 4 & rs12338 & L26V & -972.4 & Potentially unstable \\
\hline SNP: Single nucleotide polymorphism. & & & \\
\hline
\end{tabular}




\section{Research Article Chitranshi, Tiwari, Somvanshi, Tripathi \& Seth}

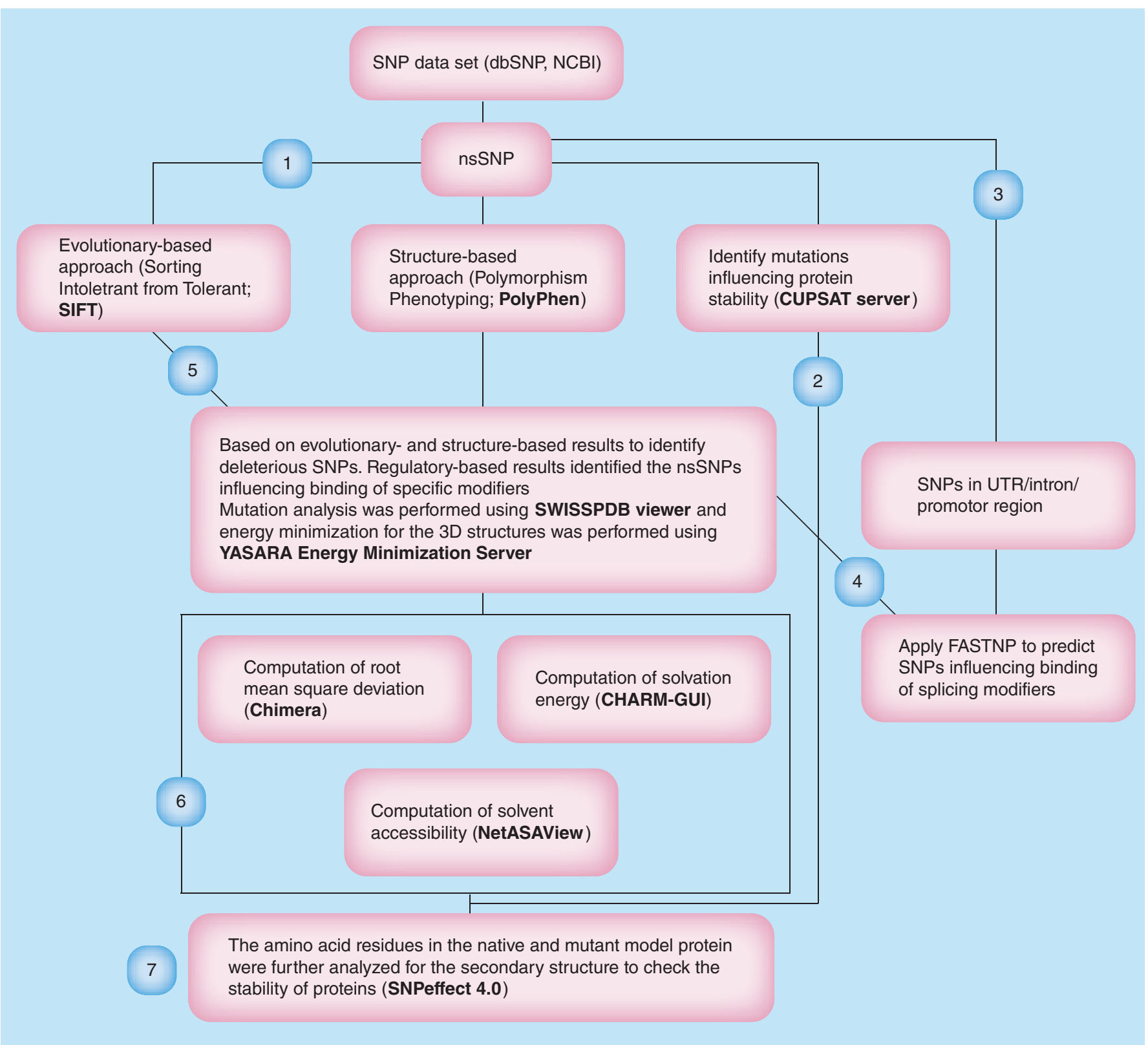

Figure 2. The processes involved in the functional assessment of single nucleotide polymorphisms by in silico methods.

1: On the basis of evaluation and structure based; 2 : influence on protein stability; 3 : on the basis of distribution; 4 : binding influence of splicing modifiers; 5: mutation analysis and energy determination; 6: root mean square deviation, solvent accessibility and solvation energy determination; 7: reporting deleterious nSSNP with secondary structure details on stability of proteins.

dbSNP: SNP database; NCBI: National Centre for Biotechnology Information; nsSNP: Nonsynonymous SNP; SNP: Single nucleotide polymorphism; UTR: Untranslated region.

greater the deviation between native and mutant type structures, which in turn changes their functional activity. The result of nsSNP rs17573 correlates with results given by SIFT, PolyPhen and the CUPSAT server. The superimposed structures of the native protein 2DCD (chain A) with the four mutant type proteins P91R, S53C, S235T and L26V of the CTSB gene are shown in shown in (Figure 1A-E).

Based on the SIFT, PolyPhen, CUPSAT, total energy and RMSD values of the mutant proteins, protein stability, solvent accessibility and secondary structure of all the residues in the native protein and mutant protein P91R, S53C, S235T and L26V of the CTSB gene were computed with PBEQ solver and NetASA. Electrostatics and solvation energies are important for defining protein stability, structural specificity and molecular recognition [52]. The electrostatic and solvation energy of dbSNP IDs rs11548596, rs1803250, rs17573, and rs12338 were found to be $-2178.4,-1567.8$, 
-670.8 and -972.4 , respectively. Two dbSNP IDs (rs11548596 and rs1803250) showed instability, one dbSNP ID (rs17573) was found to be highly unstable and one dbSNP ID (rs12338) was found to be potentially unstable (TabLE 6). Solvent accessibilities and secondary structures of amino acid residues provide a useful insight into the structure and function of a protein [5355]. In the folded structure of a protein, polar and charged side chains have higher solvent accessibility than nonpolar side chains, suggesting that formation of a hydrophobic core is a strong driving force in protein folding [56]. The prediction of residue solvent accessibility can help us to better understand the relationship between sequence and structure. The residues, namely Ala(3), Thr(120), Gly(121), Ser(152), Lys(184), Ser(185), Val(191) and Gly(198) showed a change in solvent accessibility from an buried to exposed state in the mutant protein P91R and Asp(6), Trp(11), Ser(25), Gly(27), Thr(46), Ser(51), Glu(53), Thr(61), Gly(68), Gly(70), Gly(73), Gly(74), Glu(78), Asn(81), Tyr(94), Gly(99), Ser(96), Ser(104), Gly(114),
Gly(123), Thr(125), Cys(128), Glu(133), Tyr(136), Thr(139), Tyr(146), Asn(149), Ser(150), Tyr(151), Ser(156), Glu(157), Asp(159), Glu(163), Tyr(165), Asn(167), Ser(175), Tyr(177), Ser(178), Asp(179), Tyr(183), Gly(186), Gly(193), Gly(197), Thr(212), Tyr(214), Trp(221), Asn(222), Thr(223), Gly(226), Asp(227), Gly(236), Asp(238), and Gly(241) showed a change in solvent accessibility from an exposed to buried state in the mutant protein S235T. It is interesting to note that mutant position S235T itself changed the solvent accessibility from exposed to buried state. Most of the information in the solvent accessibility features comes from the fact that buried residue positions are most likely to be adversely affected by amino acid substitutions, due to loss of structural stability [57-59]. Few studies have reported on weak interactions at the end of the secondary structural units, specifically in the $\alpha$-helix and $\beta$-sheets [57,58], which may affect the protein stability. Presence of specific amino acid residues and their local sequence is known to determine
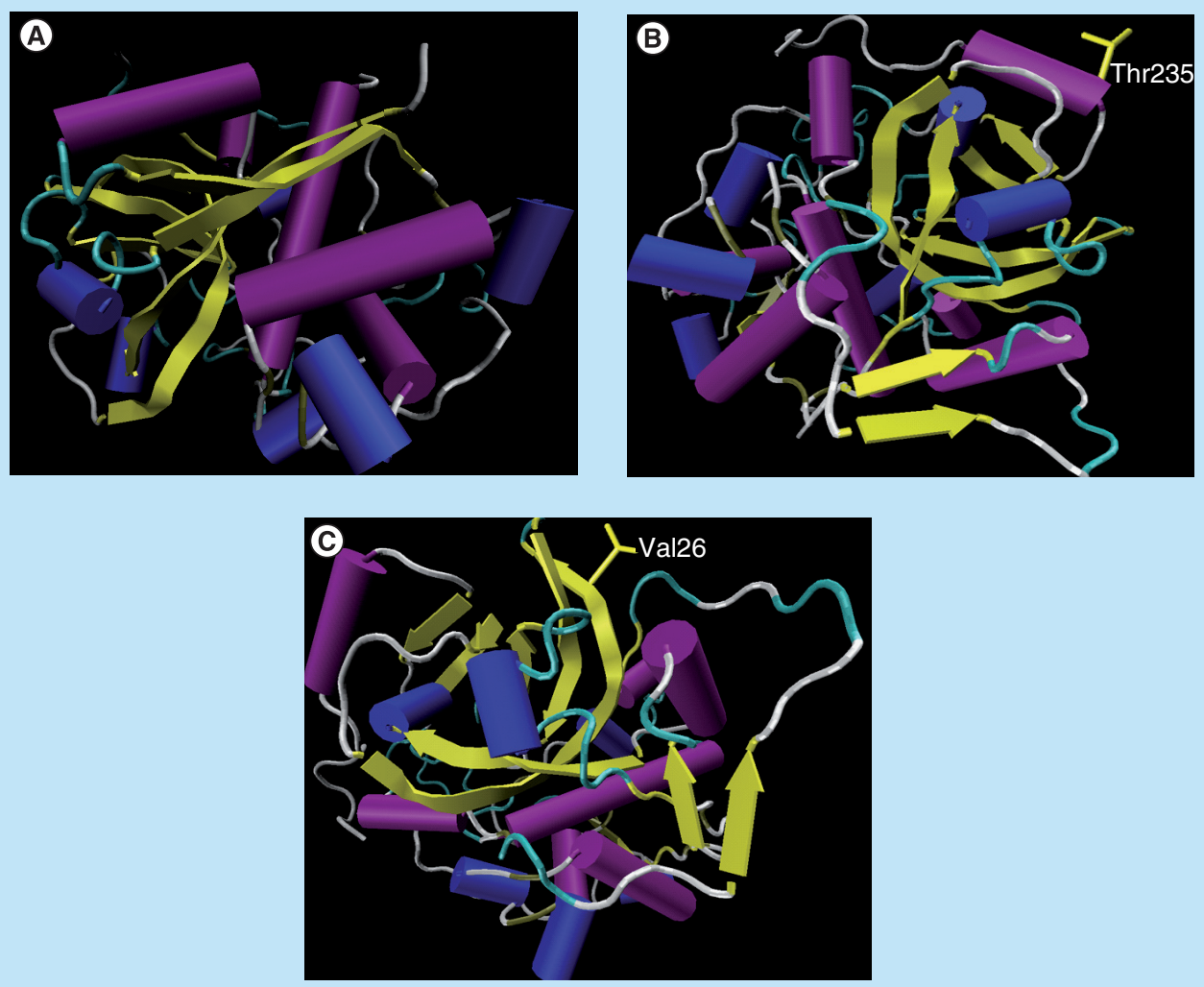

Figure 3. 3D structure changes in the native and mutant models of the CTSB protein.

(A) Native structure of the CTSB protein, Protein Data Bank ID 2DCD. (B) Mutant model of nonsynonymous single nucleotide polymorphism (rs17573) on the structure of the CTSB protein.

(C) Mutant model of nonsynonymous single nucleotide polymorphism (rs12338) on the structure of the CTSB protein. 
the protein conformation. In this study, the secondary structure of each amino acid residue was analyzed in both mutant and native structures of the protein. Residues, namely Lys(18), Gly(64), Ser(65), Met(66), Cys(67) and $A s p(143)$ were found to have changed their conformation from turn in the native protein to helix conformation in the mutant protein; Asn(219), Ser(220), Trp(221), Asp(224), Trp(225), Gly(226), Asp(227), Asn(228) and Gly(229) changed from bend to helix, $\operatorname{Trp}(11)$, Leu(12), Gln(13), Glu(19), Ile(20), Leu(181) and Leu(182) changed from helix to turn. SurpLeMENTARY Tables 1 \& 2 (see online at www.futuremedicine.com/doi/suppl/10.2217/fnl.13.26) show the secondary structure analysis and the solvent accessibility data for the mutations P91R, S53C and $\mathrm{L} 26 \mathrm{~V}$ in the CTSB gene. Thus, to understand the functional significance of changes in nsSNP, the sequence and structural data combined with solvent accessibility and secondary structure analysis should be combined. This may help us to predict the underlying causes and the molecular basis of diseases with more conviction.

\section{Conclusion \& future perspective}

The computational schematic approach shown in Figure 2 was applied to all SNPs linked to the CTSB gene cited in dbSNP. Out of 999 SNPs in the CTSB gene, 55 were nsSNPs that were analyzed using SIFT and PolyPhen algorithms. SIFT classified ten out of 55 variants $(18.18 \%)$ as 'intolerant', whereas PolyPhen classified four out of $55(7 \%)$ amino acid substitutions as 'benign, however, potentially damaging'. Evaluation of protein stability upon point mutation by the CUPSAT server showed eight nsSNPs as destabilizing to protein structure. Out of four mutant models of nsSNPs only two nsSNP (rs17573 and rs12338) mutant models demonstrated significant change in energy compare with the native structure of protein. Interestingly, two nsSNPs (rs17573 and rs12338) were predicted to be 'intolerant, probably damaging and destabilizing' by SIFT, PolyPhen and CUPSAT server, respectively, and a significant change in energy level was also observed in mutant structure (Figure 3). Of the 55 nsSNPs and 35 SNPs in coding region, the FASTSNP web server predicted that 12 SNPs influence splicing regulation and two were predicted to have a risk in the range of 3-4 (medium to high). The functional pattern change predicted by UTRscan includes PAS, IRES, MBE, K-Box, GY-Box, alcohol dehydrogenase 3'UTR downregulation control element,
TOP, SXL binding site. IRES are bound by internal mRNA ribosome. IRES is involved in the internal mRNA ribosome binding system, which controls the translational mechanisms in cell cycle [60]. MBE is an RNA-binding protein that regulates the translation of target mRNAs during neural development [61]. The primary signal used is the nuclear PAS with the sequence AAUAAA and is located toward the end of the 3'UTR. The TOP, is one of the well-characterized cis-regulatory motifs for translational controls and is located immediately downstream of the transcriptional start sites of mRNAs [62]. The following SNPs with IDs rs11548596, rs28605689 and rs12338 were found to have functional significance by both the FASTSNP server and UTRscan. Interestingly, a mutation from serine to threonine at position 235 (rs17573) on the surface of the protein caused the greatest impact on stability. Based on the PolyPhen scores and the availability of $3 \mathrm{D}$ structures, structural analysis was carried out with the major mutation that occurred in the native protein coded by CTSB genes. The total energy and RMSD value of mutant structure S235T is high when compared with the other mutants P91R, S53C and L26V in the CTSB gene. Based on the SIFT, PolyPhen, CUPSAT, total energy and RMSD values of the mutant proteins, solvent accessibility and secondary structure of all the residues in the native protein and mutant protein P91R, S53C, S253C and L26V of the CTSB gene were computed with NetASA. Solvent accessibilities and secondary structures of amino acid residues provide a useful insight into the structure and function of a protein. To predict the functional impact of SNPs, bioinformatic tools are indeed useful and our results on CTSB genes provide relevant insights into functional and haplotype tag SNPs related to Alzheimer's disease. These algorithms, based on empirical data, may have limited scope in correlating the predictive scores with the findings in the humans. Novel evidences of correlating predictive values with human data is provided in this study and it is expected that this will facilitate the future molecular epidemiological studies through genotyping efforts and provide genetic variant targets for phenotypic analysis. However, with the limited bioinformatic tools available more comprehensive approach is warranted in future analyses when more bioinformatics tools exist.

Naturally occurring mutations are of more interest in human genetics to distinguish them from functionally neutral to those contributing to diseases. Amino acid substitutions currently 
account for approximately half of the known gene lesions responsible for human inherited diseases [63]. Thus, ascertaining the association between protein functions and disease states due to nsSNPs is an important task. Possibly, due to the process of natural selection, which may have removed deleterious mutations at essential positions, many nsSNPs will have neutral effects. The challenge lies in the assessment of non-neutral SNPs, which is mainly based on phylogenetic information and certain structural approaches (PolyPhen). Increasing evidences suggest that many genetic diseases in humans are the result of exonic or noncoding mutations in the genes affecting regulatory regions [64,65]. Different methods proposed earlier were focused on modeling the SNPs responsible for causing phenotypic changes that result in differential amino acid localization. However, the current research was focused on functional SNPs affecting regulatory regions or the splicing processes. Moreover, because of their widespread distribution on the species genome, SNPs have become particularly important and valuable as genetic markers in identifying diseases and drug targets. Currently, millions of human SNPs have been reported by high-throughput methods. The vast number of SNPs presents a challenge for biologists and bioinformaticians, although they provide a lot of information about the relationships between individuals. Human genomic variation databases coupled with computational algorithms provide us with a powerful tool to assess novel polymorphisms and their effects on protein activity. A risk analysis based on the differential expression of CTSB in the symptomatic patients or asymptomatic family members could be measured for Alzheimer's disease. Further molecular testing with application of bioinformatic tools such as UTRscan, CUPSAT, FASTSNP, SIFT, PolyPhen and NetASAView may provide insight into an individual's susceptibility to Alzheimer's disease via the $C T S B$ gene.

\section{Acknowledgements}

The authors are thankful to the Indian Council of Medical Research, New Delhi, India (BIC/11(26)/2012) and the support from Department of Biotechnology, Ministry of Science and Technology, Government of India, and to Bioinformatics Centre at Biotech Park Lucknow, Uttar Pradesh, India.

\section{Financial \& competing interests disclosure}

The authors have no relevant affliations or financial involvement with any organization or entity with a financial interest in or financial conflict with the subject matter or materials discussed in the manuscript. This includes employment, consultancies, honoraria, stock ownership or options, expert testimony, grants or patents received or pending, or royalties.

No writing assistance was utilized in the production of this manuscript.

\section{Executive summary}

- The analysis of single nucleotide polymorphisms (SNPs) in the human genome provides a key understanding to the relevance of genetic variation in a number of diseases, such as Alzheimer's disease, one of the most common forms of dementia.

- Genome-wide association linkage has gained popularity in recent times, but the true utility of the studies remain uncertain.

- It has been documented experimentally that genome-wide association studies identified the APOE linkage disequilibrium region as the strongest genetic risk factor for Alzheimer's disease.

- There are many other SNPs yet to be identified and studied that may be directly or indirectly linked to Alzheimer's disease.

- The application of computational algorithms for predicting the association of SNPs to diseases could be an active tool to gain insight even at the early stages of disease progression.

- Due to overabundance of SNPs, it is not an easy exercise to explore every SNP experimentally. However, some important SNPs may affect coding and regulatory regions.

\section{References}

1. Sachidanandam R, Weissman D, Schmidt SC et al. A map of human genome sequence variation containing 1.42 million single nucleotide polymorphisms. Nature 409(6822), 928-933 (2001).

2. Yuan Q, Zhou Z, Lindell SG et al. The rhesus macaque is three times as diverse but more closely equivalent in damaging coding variation as compared to the human. $B M C$ Genet. 13, 52 (2012).
3. Vishnoi A, Sethupathy P, Simola D, Plotkin JB, Hannenhalli S. Genome-wide survey of natural selection on functional, structural, and network properties of polymorphic sites in Saccharomyces paradoxus. Mol. Biol. Evol. 28(9), 2615-2627 (2011).

4. Broniarczyk J, Olejnik-Schmidt AK, Luczak MW et al. Analysis of expression and structure of the TSG101 gene in cervical cancer cells. Int. J. Mol. Med. 25(5), 777-783 (2010).

5. Fredman D, Siegfried M, Yuan YP, Bork P, Lehvaslaiho H, Brookes AJ. HGVbase: a human sequence variation database emphasizing data quality and a broad spectrum of data sources. Nucleic Acids Res. 30(1), 387-391 (2002).

6. Hirakawa M, Tanaka T, Hashimoto Y, Kuroda M, Takagi T, Nakamura Y. JSNP: a database of common gene variations in the Japanese population. Nucleic Acids Res. 30(1), 158-162 (2002)

7. Wang Z, Moult J. SNPs, protein structure, and disease. Hum. Mutat. 17(4), 263-270 (2001). 
8. Sunyaev S, Ramensky V, Koch I, Lathe W 3rd, Kondrashov AS, Bork P. Prediction of deleterious human alleles. Hum. Mol. Genet. 10(6), 591-597 (2001).

9. Stitziel NO, Binkowski TA, Tseng YY, Kasif S, Liang J. TopoSNP: a topographic database of non-synonymous single nucleotide polymorphisms with and without known disease association. Nucleic Acids Res. 32, D520-D522 (2004).

10. Yip YL, Scheib H, Diemand AV et al. The Swiss-Prot variant page and the ModSNP database: a resource for sequence and structure information on human protein variants. Hum. Mutat. 23(5), 464-470 (2004).

11. Karchin R, Diekhans M, Kelly L et al. LS-SNP: large-scale annotation of coding non-synonymous SNPs based on multiple information sources. Bioinformatics 21(12), 2814-2820 (2005).

12. Reumers J, Schymkowitz J, Ferkinghoff-Borg J, Stricher F, Serrano L, Rousseau F. SNPeffect: a database mapping molecular phenotypic effects of human non-synonymous coding SNPs. Nucleic Acids Res. 33(Database issue), D527-D532 (2005).

13. Dantzer J, Moad C, Heiland R, Mooney S. MutDB services: interactive structural analysis of mutation data. Nucleic Acids Res. 33(Web Server issue), W311-W314 (2005).

14. Li S, Ma L, Li H et al. Snap: an integrated SNP annotation platform. Nucleic Acids Res. 35(Database issue), D707-D710 (2007).

15. Kirschke H, Barrett AJ, Rawlings ND. Proteinases 1: lysosomal cysteine proteinases. Protein Profile 2(14), 1581-1643 (1995).

16. Hook VY, Toneff T, Aaron W, Yasothornsrikul S, Bundey R, Reisine T. $\beta$-amyloid peptide in regulated secretory vesicles of chromaffin cells: evidence for multiple cysteine proteolytic activities in distinct pathways for $\beta$-secretase activity in chromaffin vesicles. J. Neurochem. 81(2), 237-256 (2002).

17. Hook V, Toneff T, Bogyo M et al. Inhibition of cathepsin B reduces $\beta$-amyloid production in regulated secretory vesicles of neuronal chromaffin cells: evidence for cathepsin B as a candidate $\beta$-secretase of Alzheimer's disease. Biol. Chem. 386(9), 931-940 (2005).

18. Hook VY, Kindy M, Hook G. Inhibitors of cathepsin B improve memory and reduce $\beta$-amyloid in transgenic Alzheimer disease mice expressing the wild-type, but not the Swedish mutant, $\beta$-secretase site of the amyloid precursor protein. J. Biol. Chem. 283(12), 7745-7753 (2008).

19. Fong D, Chan MM, Hsieh WT, Menninger JC, Ward DC. Confirmation of the human cathepsin B gene (CTSB) assignment to chromosome 8. Hum. Genet. 89(1), 10-12 (1992).

20. Diederich S, Sauerhering L, Weis M et al. Activation of the Nipah virus fusion protein in MDCK cells is mediated by cathepsin B within the endosome-recycling compartment. J. Virol. 86(7), 3736-3745 (2012).

21. Mordier S, Bechet D, Roux MP, Obled A, Ferrara M. Nucleotide sequence of bovine preprocathepsin B. A study of polymorphism in the protein coding region. Biochim. Biophys. Acta 1174(3), 305-311 (1993).

22. Gil M, S’Arraca C. Solation and characteristics of a porcine muscle cysteine proteinase inhibitory fraction. Food Biotechnol. 11, 59-71 (1997).

23. Rajasekaran R, Sethumadhavan R. In silico identification of significant detrimental missense mutations of EGFR and their effect with 4-anilinoquinazoline-based drugs. Appl. Biochem. Biotechnol. 160(6), 1723-1733 (2010).

24. Kanthappan R, Sethumadhavan R. Identification of structurally and functionally significant deleterious nsSNPs of GSS gene: in silico analysis. Adv. Biosci. Biotechnol. 1 , 361-366 (2010).

25. Singh AA, Shivakumar D, Somvanshi P. Cataloguing functionally relevant polymorphisms in gene DNA ligase I: a computational approach. 3 Biotech 1, 47-56 (2011).

26. Sherry ST, Ward MH, Kholodov M et al. dbSNP: the NCBI database of genetic variation. Nucleic Acids Res. 29(1), 308-311 (2001).

27. Ng PC, Henikoff S. Predicting deleterious amino acid substitutions. Genome Res. 11(5), 863-874 (2001).

28. Ng PC, Henikoff S. Accounting for human polymorphisms predicted to affect protein function. Genome Res. 12(3), 436-446 (2002).

29. Kumar P, Henikoff S, Ng PC. Predicting the effects of coding non-synonymous variants on protein function using the SIFT algorithm. Nat. Protoc. 4(7), 1073-1081 (2009).

30. Sunyaev SR, Eisenhaber F, Rodchenkov IV, Eisenhaber B, Tumanyan VG, Kuznetsov EN. PSIC: profile extraction from sequence alignments with position-specific counts of independent observations. Protein Eng. 12(5), 387-394 (1999).

31. Ramensky V, Bork P, Sunyaev S. Human non-synonymous SNPs: server and survey. Nucleic Acids Res. 30(17), 3894-3900 (2002).

32. Adzhubei IA, Schmidt S, Peshkin L et al. A method and server for predicting damaging missense mutations. Nat. Methods 7(4), 248-249 (2010).
33. Yuan HY, Chiou JJ, Tseng WH et al. FASTSNP: an always up-to-date and extendable service for SNP function analysis and prioritization. Nucleic Acids Res. 34, W635-W641 (2006).

34. Cartegni L, Wang J, Zhu Z, Zhang MQ, Krainer AR. ESEfinder: a web resource to identify exonic splicing enhancers. Nucleic Acids Res. 31(13), 3568-3571 (2003).

35. Fairbrother WG, Yeh RF, Sharp PA, Burge CB. Predictive identification of exonic splicing enhancers in human genes. Science 297(5583), 1007-1013 (2002).

36. Wang Z, Rolish ME, Yeo G, Tung V, Mawson $M$, Burge CB. Systematic identification and analysis of exonic splicing silencers. Cell 119(6), 831-845 (2004).

37. Sonenberg N. mRNA translation: influence of the 5' and 3' untranslated regions. Curr. Opin. Genet. Dev. 4(2), 310-315 (1994).

38. Nowak R. Mining treasures from 'junk DNA'. Science 263(5147), 608-610 (1994).

39. Pesole G, Liuni S. Internet resources for the functional analysis of $5^{\prime}$ and $3^{\prime}$ untranslated regions of eukaryotic mRNAs. Trends Genet. 15(9), 378 (1999).

40. Pesole G, Liuni S, Grillo G et al. UTRdb and UTRsite: specialized databases of sequences and functional elements of 5' and 3' untranslated regions of eukaryotic mRNAs. Update 2002. Nucleic Acids Res. 30(1), 335-340 (2002).

41. De Baets G, Van Durme J, Reumers J et al. SNPeffect 4.0: on-line prediction of molecular and structural effects of protein-coding variants. Nucleic Acids Res. 40(Database issue), D935-D939 (2012).

42. Krieger E, Joo K, Lee J et al. Improving physical realism, stereochemistry, and side-chain accuracy in homology modeling: four approaches that performed well in CASP8. Proteins 77(Suppl. 9), S114-S122 (2009).

43. Krieger E, Koraimann G, Vriend G. Increasing the precision of comparative models with YASARA NOVA - a selfparameterizing force field. Proteins 47(3), 393-402 (2002).

44. Jo S, Vargyas M, Vasko-Szedlar J, Roux B, Im W. PBEQ-Solver for online visualization of electrostatic potential of biomolecules. Nucleic Acids Res. 36(Web Server issue), W270-W275 (2008).

45. Ahmad S, Gromiha M, Fawareh H, Sarai A. ASAView: database and tool for solvent accessibility representation in proteins. $B M C$ Bioinformat. 5, 51 (2004).

46. Gilis D, Rooman M. Stability changes upon mutation of solvent-accessible residues in proteins evaluated by database-derived 
potentials. J. Mol. Biol. 257(5), 1112-1126 (1996).

47. Gilis D, Rooman M. Predicting protein stability changes upon mutation using database-derived potentials: solvent accessibility determines the importance of local versus non-local interactions along the sequence. J. Mol. Biol. 272(2), 276-290 (1997).

48. Kabsch W, Sander C. Dictionary of protein secondary structure: pattern recognition of hydrogen-bonded and geometrical features. Biopolymers 22(12), 2577-2637 (1983).

49. Krawczak M, Ball EV, Fenton I et al. Human gene mutation database - a biomedical information and research resource. Hum. Mutat. 15(1), 45-51 (2000).

50. Han JW, Zheng HF, Cui Y et al. Genome-wide association study in a Chinese Han population identifies nine new susceptibility loci for systemic lupus erythematosus. Nat. Genet. 41(11), 1234-1237 (2009).

51. Onouchi Y, Ozaki K, Burns JC et al. A genome-wide association study identifies three new risk loci for Kawasaki disease. Nat. Genet. 44(5), 517-521 (2012).

52. Pokala N, Handel TM. Energy functions for protein design I: efficient and accurate continuum electrostatics and solvation. Protein Sci. 13(4), 925-936 (2004).

53. Eyal E, Najmanovich R, McConkey BJ, Edelman M, Sobolev V. Importance of solvent accessibility and contact surfaces in modeling side-chain conformations in proteins. J. Comput. Chem. 25(5), 712-724 (2004).
54. Russell SJ, Blandl T, Skelton NJ, Cochran AG. Stability of cyclic $\beta$-hairpins: asymmetric contributions from side chains of a hydrogen-bonded cross-strand residue pair. J. Am. Chem. Soc. 125(2), 388-395 (2003).

55. Totrov M. Accurate and efficient generalized born model based on solvent accessibility: derivation and application for $\log \mathrm{P}$ octanol/water prediction and flexible peptide docking. J. Comput. Chem. 25, 609-619 (2003).

56. Chan HS, Dill KA. Origins of structure in globular proteins. Proc. Natl Acad. Sci. USA 87(16), 6388-6392 (1990).

57. Madan Babu M, Singh KS, Balaram P. C-H triplebond $\mathrm{O}$ hydrogen bond stabilized polypeptide chain reversal motif at the $\mathrm{C}$ terminus of helices in proteins. J. Mol. Biol. 322(4), 871-880. (2002).

58. Fabiola GF, Krishnaswamy S, Nagarajan V, Pattabhi V. C-H...O hydrogen bonds in $\beta$-sheets. Acta Crystallogr. D. Biol. Crystallogr. 53(Pt 3), 316-320 (1997).

59. Markiewicz P, Kleina LG, Cruz C, Ehret $S$, Miller JH. Genetic studies of the lac repressor. XIV. Analysis of 4000 altered Escherichia coli lac repressors reveals essential and nonessential residues, as well as 'spacers' which do not require a specific sequence. J. Mol. Biol. 240(5), 421-433 (1994).

60. Raevaara TE, Korhonen MK, Lohi $\mathrm{H}$ et al. Functional significance and clinical phenotype of nontruncating mismatch repair variants of MLH1. Gastroenterology 129(2), 537-549 (2005).
61. Macnicol AM, Wilczynska A, Macnicol MC. Function and regulation of the mammalian Musashi mRNA translational regulator. Biochem. Soc. Trans. 36(Pt 3), 528-530 (2008).

62. Amaldi F, Pierandrei-Amaldi P. TOP genes: a translationally controlled class of genes including those coding for ribosomal proteins. Prog. Mol. Subcell Biol. 18, 1-17 (1997).

63. Cooper DN, Ball EV, Krawczak M. The human gene mutation database. Nucleic Acids Res. 26(1), 285-287 (1998).

64. Hudson TJ. Wanted: regulatory SNPs. Nat. Genet. 33(4), 439-440 (2003).

65. Yan H, Yuan W, Velculescu VE, Vogelstein B, Kinzler KW. Allelic variation in human gene expression. Science 297(5584), 1143 (2002).

\section{Websites}

101. dbSNP. www.ncbi.nlm.nih.gov/snp

102. HapMap Project. http://hapmap.ncbi.nlm.nih.gov

103. PolyPhen-2. http://genetics.bwh.harvard.edu/pph2

104. CUPSAT. http://cupsat.tu-bs.de

105. FastSNP. http://fastsnp.ibms.sinica.edu.tw

106. CHARMM. www.charmm-gui.org

107. NetASAView. www.netasa.org 